\title{
EFICÁCIA DAS DECISÕES DA UNIÃO EUROPÉIA E DO MERCOSUL
}

Juliana Kiyosen Nakayama

SUMÁRIO: 1. Introdução. 2. Apontamentos sobre a União Européia. 3. Apontamentos sobre o Mercosul. 4. Eficácia das decisóes da União Européia e do Mercosul. 5. Conclusão. 6. Bibliografia.

SUMMARY: 1. Introduction. 2. Notes on the Européia Union. 3. Notes on the Mercosul. 4.Effectiveness of the decisions of the Européia Union and the Mercosul. 5. Conclusion. 6.Bibliography.

SUMARIO: 1.Introducción. 2. Notas sobre la Unión Europea. 3. Notas sobre el MERCOSUR. 4. Eficacia de las decisiones de la Unión Europea y el MERCOSUR. 5.Conclusión. 6.Bibliografia.

RESUMO: O presente artigo faz um panorama geral sobre a União Européa e o Mercosul, compara a estrutura juridica de ambos os blocos para fazer uma comparação da eficácia das decisões da União Européia e do Mercosul, colocando frente a frente a supranacionalidade e a intergovernamentabilidade.

ABSTRACT: The present article makes a general panorama of Europen Union and MERCOSUR, comparing legal structure of both blocks to analyse effectiveness EU decisions and the Mercosur's, being placed front to front supranationality and intergovernamentability.

Mestre en Direito Negocial pela Universidade Estadual de Londrina. Professora da Faculdade Pananense - FACCAR 
RESUMEN: El artículo hace un panorama general de la Unión Europea y el MERCOSUR, compara la estructura legal de los bloques para hacer una comparación de la eficacia de las decisiones de la Unión Europea y del MERCOSUR, siendo frente puesto el frente la supranacionalidad y la intergovernamentabilidad.

PALAVRAS-CHAVE: Mercosul. União Européia. Decisão. Eficácia. Supranacionalidade. Intergovernamentabilidade.

KEY-WORDS: Mercosur. European Union. Decision. Effectiveness. Supranationality. Intergovernamentability.

PALABRAS-LLAVE: MERCOSUR. Unión Europea. Decisión. Eficácia. Supranacionalidad. Intergovernamentabilidad.

\section{Introdução}

O presente artigo faz um panorama geral sobre a União Européia e o Mercosul, compara a estrutura jurídica de ambos os blocos para denotar semelhanças e diferenças da eficácia das decisões da União Européia e do Mercosul.

Tendo em vista as características de cada bloco econômico, as decisões no Mercosul pautam-se pela intergovernamentabilidade e da União Européia pela supranacionalidade.

\section{Apontamentos sobre a união européia}

A União Européia, como bloco econômico, é um êxito. Desde a metade do século passado, a Europa vive em paz. Cinqüenta anos depois de seu nascimento, a União Européia passa por um momento de reflexão sobre a sua existência. A unificação da Europa é iminente, fato em transformação, onde irá superar uma das páginas mais sombrias da sua história, a segunda guerra mundial. A Europa vai converter-se em um bloco forte em definitivo, sem guerras bélicas.

Apesar da conjuntura atual, o desenvolvimento da União Européia confirma a vastidão do seu potencial e a sua colocação como uma das potências econômicas mundiais. 
Convém salientar que as fontes do Direito comunitário podem ser divididas em Direito primário e Direito secundário. Entre o Direito primário, estão os textos institutivos ${ }^{1}$, entre outros, o Tratado que institui a Comunidade Européia do Carvão e do Aço (CECA), assinado em Paris, em 18/04/ 1951, em vigor desde 23/07/1952; Tratados que instituem a Comunidade Econômica Européia (CEE) e Comunidade Européia da Energia Atômica (CEEA), assinados em Roma, 25/03/1957; Tratados de adesão do Reino Unido, Irlanda, Dinamarca - 22/01/1972, da Grécia - 28/05/1979, da Espanha e Portugal - 12/06/1985, da Áustria, Suécia, Finlândia - 25/06/1994; o Ato Único Europeu, assinado em 17 e 28/02/1986 e em vigor desde 01/07/1987; Tratado da União Européia, assinado em Maastricht em 07/02/1992 e em vigor desde 01/11/1993; Tratados de fusão dos executivos, 08/04/1965; Tratados financeiros, 22/04/1970 e de 22/07/1975; Tratado de Amsterdã, assinado em 02/10/1997 e o Tratado de Nice.

A União Européia está localizada na parte ocidental da Europa e tem como países membros: Alemanha, Áustria, Bélgica, Dinamarca, Espanha, Finlândia, França, Grécia, Holanda, Irlanda, Itália, Luxemburgo, Portugal, Reino Unido e Suécia. Essa União Econômica visa a criação de um mercado interno único, com uma moeda própria, o Euro, e um sistema financeiro e bancário comum. A União Européia, da mesma forma, prevê a unificação das políticas externas e de defesa, das leis trabalhistas, de imigração e de combate ao crime, além de garantir cidadania única para todos os habitantes dos países membros.

Os moldes beligerantes foram substituídos pela idéia de integração, onde a paz perpétua foi o mais alto ideal a ser alcançado pela humanidade, o caminho para a verdadeira União Européia. Kant sustenta que as guerras decorriam do sentimento dos monarcas, com espírito de Estado como propriedade particular, sendo que a República seria a forma mais pacífica regime de governo?2.

Nesse clima de dependência e de debilidade política e econômica dos Estados europeus, após a Segunda Guerra Mundial, aflorou a certeza da necessidade de uma Europa unida ${ }^{3}$.

Em 05 de maio de 1949, foi criado o Conselho da Europa, em Estrasburgo, que foi a primeira instituição européia ocidental. Em 04 de

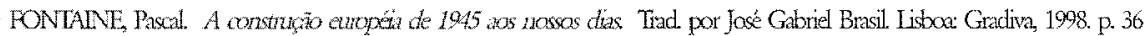
MEIRELLES, José Ricardo. Impostos indiretos no Morcosul e integração. São Paulo: Ltr, 2000, p.19. Ibiden, p.22 
novembro de 1950, originou-se o Tribunal Europeu para a Salvaguarda dos Direitos do Homem e das Liberdades Fundamentais, hoje chamado de Tribunal Europeu para a Salvaguarda dos Direitos do Homem, que é o último recurso dos cidadãos dos 40 Estados membros do Conselho da Europa.

Pondere-se, contudo, que o Tribunal Conselho da Europa tem um catálogo de Direitos fundamentais que não correspondem ao desenvolvimento de hoje $\mathrm{e}^{4}$. Esse catálogo enuncia, ainda, que os direitos dos cidadãos perante os tribunais devem obedecer ao devido processo legal para ambas as partes. Estrasburgo é a sede do Tribunal Conselho da Europa. Para suspender os Direitos de um Estado membro, há necessidade de unanimidade, o que gera ineficácia. A Turquia é membro do Conselho da Europa e não da União Européia. Esse Estado quer entrar, mas 99\% de seu território năo pertencem à Europa. Necessita-se de requisitos mínimos para ser parte da União Européia.

Ressalta-se o Tratado de Paris, de 1951, que declarou a necessidade da França e da Alemanha produzirem conjuntamente carbono e aço para acabar com a rivalidade secular entre ambos paises. O Tratado de Paris criou a CECA, embrião da construção européia.

O projeto CECA representava, sobretudo, um primeiro esforço de construção européia, valendo-se de novos métodos; tratava-se de preparar a comunidade política, começando pela construção de uma Comunidade Econômica. Surgia a concessão de uma construção funcional da Europa, criando uma solidariedade de fato. O Tratado da CECA era inspirado na criação, no setor do carvão e do aço, de um mercado comum sem obstáculos nas fronteiras e sem distorções de concorrência, com o fim de promover o desenvolvimento das atividades econômicas ${ }^{5}$.

A finalidade e o fundamento dessa primeira comunidade eram, precisamente, a instituição de um mercado europeu carbosiderúrgico consistente em uma área de livre comércio entre os países membros, fundada sobre a abolição de determinadas condições e, dentro de um determinado período de tempo, dos impostos de entrada e saída e das taxas de efeito equivalente, bem como das restrições quantitativas à circulação dos produtos. Outra finalidade importante era a supressão das medidas e das práticas discriminatórias entre produtores, entre adquirentes ou entre consumidores, especialmente no tocante às condições de preço ou de custódia e às tarifas de transporte de produtos'.

+ Como por exemplo, do Catálogo de Direitos Fundamentais do Thburnal Conselho da Europa, protbinco a escravidão. ${ }^{5}$ FORTE, Umberto. Unzào Européra Comunidade Econômica Européia Direito das comunidades européias e harmonização fiscal. trad. por Ana Tereza Marino Falcao. São Paulo: Malheiros, 1994. p.48/49.

"Ibidem. 
É certo, porém, que do Tratado de Roma, de 1957, originou a atual União Européia, a Comunidade Econômica e a Comunidade Européia de Energia Atômica. As três citadas dispõem de assembléia, comissões, conselho de ministros e tribunal de justiça. Os países que assinaram o Tratado de Roma foram considerados os fundadores da União Européia: Itália, França, Alemanha, Bélgica, Holanda e Luxemburgo. Em 1973, entram na União Européia a Dinamarca, Grã Bretanha e Irlanda. Em 1979, originou-se o remoto Euro, limitando a $2,25 \%$ a margem de flutuação das moedas para controlar a inflação. Em 1981, a Grécia ingressa na União Européia e em 1986, Espanha e Portugal. Em 1986, o Ato Unico Europeu fornece o caráter democrático da comunidade para conceder novos poderes para 0 Parlamento europeu e amplia os âmbitos de atuação comunitária nas áreas de meio ambiente, pesquisa e desenvolvimento. Em 1988, um comitê de peritos, presidido pelo presidente da Comissāo européia, Jacques Delors, detalhou um plano para a consecução do mercado interno, a livre circulação de capitais e a convergência econômica?

Após apresentar algumas características históricas quanto aos tratados que são fonte primána do bloco, passa-se a discorrer sobre o objetivo da União Européia.

Pelo dito anteriormente, esta união econômica é caracterizada pela livre circulação de mercadorias, com redução ou com eliminação de barreiras tarifárias, com técnicas de saída para mercadorias produzidas dentro desse mercado e pela implantação de uma política tarifária externa comum.

A União Européia, com o Tratado de Maastricht de 1992 impulsiona a maior reforma das instituições européias. Substitui-se a Comunidade Econômica Européia pela União Européia, implanta-se progressivamente a plena união monetária e a moeda única. Houve a coesão econômica e social e o conceito de cidadania européia e se incrementam os campos de atuação comunitária. Com a crise do sistema monetário em 1993, os movimentos especulativos póem em dúvida a estabilidade da moeda européia. As vacilações iniciais dos governos europeus para combate somente se superaram com drásticas intervenções dos bancos centrais ${ }^{8}$.

Em 31.12.1992, com o início do funcionamento do mercado europeu interno, surgiu uma nova fase para o Direito tributário dos Estados-membros da União Européia, na medida que os sistemas tributários dotados de muitas estruturas de pressão fiscal passaram a concorrer entre si sem a proteção de fronteiras fiscais ${ }^{9}$.

\footnotetext{
EUROPA. A nova Europa e história. Disponivel em http:/wwwelpais.es/temas/ue/menud/ menud6.html. Acesso em 12 nov. 2001, p.1

"Tbidem, p.1-2

"TORRES, Heleno. Phunithutacio intemacional sobre as rendas de empresas. 2 ed. rev, atual. e ampí. Săo Paulo: Revista dos Tribunais, 2001, p.725
} 
Por essa acepção, a união é o primeiro passo para os Estados se unirem, uniăo é mais conceito político, diferente de comunidade. A CE é instituição estática. A União Européia é instituição política, com mais movimento e dinâmica. O cidadão é da UE e não da CE. Cidadania comum da União Européia estão no Tratado de Roma. Em 1995, ingressam na União Européia a Áustria, a Finlândia e a Suécia.

Em 1997, o Tratado de Amsterdã, de menor alcance que o Tratado de Maastricht, teve prioridade para aproximar a União Européia para as preocupações de seus cidadãos. Realizam-se acordos sobre seguros, sobre empregos, sobre política exterior, sobre defesa e sobre a legitimidade das instituições européias. O Tratado de Amsterdã é o Tratado de Roma e o Tratado de Maastricht - reformados e ratificados em 1999 -, em vigor desde maio de 1999. O Tratado de Amsterdã mudou os números dos artigos e intensificou a integração da Europa.

Sobreleva aqui, onde o Conselho Europeu de Bruxelas decidiu sobre os países aspirantes a formar a união monetária: Alemanha, Áustria, Bélgica, Espanha, Finlândia, França, Holanda, Irlanda, Itália, Luxemburgo e Portugal, em 1998, e, em 2001, incorporam-se Dinamarca, Reino Unido, Suécia e Grécia. O Tratado de Nice, de 2001, instaurou o novo e completo sistema de repartição de poder na União Européia, quando nesta ingressam os países do centro leste europeu ${ }^{10}$.

Assim, os órgãos da União Européia são: o conselho de ministros é o Conselho da União Européia, que é uma reunião dos ministros com 87 votos no total, com cada país tendo direito de 1 a 10 votos cada, conforme a importância do país. Por exemplo, Luxemburgo com 2 votos e França com 10; o Conselho da União Européia, instituição política, sediada em Bruxelas e com voto por maioria qualificada com $2 / 3$. Em questões fundamentais há necessidade de unanimidade ${ }^{11}$. A União Européia não é um Estado, é algo semelhante à confederação. A comissão da União Européia é o Poder Executivo, com direito à iniciativa legiferante. Tarefas dessa comissão: iniciativa e administração da União Européia. Essa comissão tem 20.000 funcionários. A maioria são tradutores. Metade do orçamento europeu vai para a agricultura porque tem de ser protegida, na visão dos europeus, e também com impostos alfandegários para proteger a agricultura.

in EUROPA. A nova Europa e história. Disponível em http//www.elpais.es/temas/ue/menud/ menud6.html. Acesso em 12 nov. 2001. p.12

"Por exemplo, caso de entrada de novo membro. 
Tendo em vista a justificativa dada anteriormente sobre a importância de discorrer sobre os órgãos da União Européia, dar-se-á continuidade ao tema. Em vista disso, o Parlamento europeu, outro dos órgãos da União Européia, consta de 626 membros, o número de deputados não é proporcional ao número de habitantes. Não há uma nação européia com uma verdadeira democracia. O Parlamento europeu não tem vida própria, é um órgão de controle perante o Conselho da União Européia. O Parlamento europeu pode derrubar toda a Comissão da União européia. Para um comissário atuar, necessita de aprovação do Parlamento europeu; não possui todas as competências de um Parlamento propriamente dito; tem como membros 626 eleitos por cinco anos agrupados por afinidades políticas; 99 da Alemanha, 87 da França, Itália, Reino Unidos, 64 da Espanha, 31 dos Países Baixos, 25 da Bélgica, Grécia e Portugal, 22 da Suécia, 21 da Austria, 16 da Dinamarca e Finlândia, 15 da Irlanda, 6 de Luxemburgo. Com sedes em Estrasburgo para sessões plenárias; Bruxelas, para reuniões das comissões, e Luxemburgo com a secretaria geral.

A rigor, as competências do parlamento são demonstradas na participação do processo administrativo de decisão, poder de co-decisão com o conselho; exercendo competência consultiva; estabelecimento do orçamento comunitário, aprovando ou rejeitando, juntamente com o conselho, o orçamento elaborado pela comissão; controle político da comissão ou conselho que designa questões orais e escritas, mais moção de censura, com demissão da comissão e a cooperação institucional ${ }^{12}$.

Cumpre mencionar, também, outro órgão sendo o Conselho europeu, semelhante ao chefe de Estado. O Conselho europeu é diferente do Conselho da Europa. Reúne-se pelo menos duas vezes ao ano, contando com a presença do presidente da Comissão, na qualidade de membro de Direito. Apresenta, por atribuição, a responsabilidade de abordar os problemas da atualidade internacional, por intermédio da cooperação política européia, mecanismo de aproximação que the permite definir, por meio das declarações e das conclusões que aprova, atitudes comuns tomadas em nome da União ${ }^{13}$.

A propósito, a conferência diplomática de Nice, ocorrida em dezembro de 2001 foi muito polêrmica face ao esforço político-jurídico para abrigar vinte e sete Estados-membros. Numerosos Estados de porte médio contentam-se que a

\footnotetext{
SILVA, Roberto Luiz. Direito comunitário e da integração, Porto Alegre: Śntese, 1999. p.58 13. Ibidem, p.55
} 
Europa seja um grande mercado necessário às empresas e não vêem necessidade de uma grande potência européia. Uma nova Conferência Intergovernamental terá lugar em 2004, com pauta de discussão constitucional: delimitação das competências entre a União e os Estados-membros; estatuto da Carta Européia dos Direitos Fundamentais; simplificação dos tratados e a função dos parlamentares nacionais na arquitetura européia ${ }^{14}$.

O texto da Declaração de Laeken é um guia para debate do futuro da União Européia. A partir de março de 2002, muitas perguntas têm de ser respondidas por uma convenção criada pelos Chefes de Estado e de Governo. Entre as perguntas estão, como controlar a União Européia como um desafio democrático da transparência? Qual o papel da Europa depois do ocorrido em 11 de setembro nos Estados Unidos? Como diminuir a pobreza e o desemprego? Como clarear as competências dos Estados-membros e do bloco sem distorções? Como diminuir os instrumentos legislativos para simplificá-los? Para uma Constituição, quais os elementos essenciais para este texto constitucional ${ }^{15}$ ?

Comentou-se sobre os aspectos gerais da União Européia para se visualizar o bloco inserto no mundo que tende a ser globalizado.

\section{Apontamentos sobre o Mercosul}

Em 26 de março de 1991, originou-se o Mercado Comum do Sul (MERCOSUL), através do Tratado de Assunção ${ }^{16}$, tendo como membros, Argentina, Brasil, Paraguai e o Uruguai. O Tratado de Assunção declara a intenção de constituir um mercado comum.

Seja como for, de acordo com o Tratado de Assunção, o MERCOSUL fica aberto para adesões, mediante negociações com países membros da Associação Latino Americana de Integração ${ }^{17}$. Assim, desde agosto de 1995, a Bolívia e o Chile assumiram um compromisso no Tratado de Assunção, tornando-se, assim, Estados-associados ao MERCOSUL.

\footnotetext{
it VENTURA, Deisy de Freitas Lima. O futuro da União Européia: um balanço do Tratado de Nice e dos desafios da CIG 2001. In: PIMENTEL, Luiz Otávio. (org.) Direito da integração: estudos em homenagem a Werter R. Faria. Curitiba: Turuá, 2001. vol. 1, p.215.

${ }_{15}^{15}$ CAÑAS, Gabriela. CUMBRE DE LA UE. La Declaración de Laeken. Los jefes de Estado y de Gobierno de los Quince debatirán desde marzo el futuro de la UE. In: El Pais. Disponível em http:www.elpais.es/ articulo.html?xref=20011216elpepiint_18type-Tes\&anchor-elpepiint\&d_date-2001121. Acesso em $17 \mathrm{dez} .2001$. In Incorporado no Direito brasileiro através do Decreto n.350, de 21 nov. 1991. Pelo Decreto Legislativo 197/91, publicado no Diário Oficial da União de 26 set. 1991, p. 20.781.

${ }^{17}$ Capítulo IV - Adesão - Art. 20 do Tratado de Assunção. O presente Tratado estará aberto à adesão mediante negociaçĩo, dos demais países-membros da Associação Latino-Atnericana de Integração, cujas solicitaçôes poderĩo ser examinadas pelos Estados Partes depois de cinco anos de vigência deste Tratado. Não obstante, poderão ser consideradas antes do referido prazo as solicitações apresentadas por países-membros da Associação Latino-Americana de Integração que não façam parte de esquemas de integração subregional ou de uma associação extra-regional. A aprovação das solicitações setá objeto de decisão unânime dos Estados Pattes.
} 
Por isso, não é demais enfatizar, nesta futura etapa do mercado comum, considerado um estágio mais aprofundado que compreende a livre circulação de todos os fatores de produção com a eliminação de barreiras e o estabelecimento de uma tarifa externa comum para países signatários do Tratado de Assunção, implica na aplicação das cinco liberdades que são a livre circulação de mercadorias, a liberdade de estabelecimento, a livre circulação de trabalhadores, a livre circulação de capitais e a liberdade de concorrência.

Ponderações desse jaez permitem compreender que o Tratado de Assunção têm com princípios orientadores, para o alcance de seus objetivos, a flexibilidade, a gradualidade, o equilíbrio e a reciprocidade. Esses objetivos foram explicados no capítulo sobre o processo de integração.

Antes da entrada em vigor do Tratado de Assunção há uma primeira classificação do Direito do MERCOSUL em a) Direito originário ou primário ${ }^{18}$ constante do Tratado de Assunção e seus Anexos e b) Direito derivado ou secundário ${ }^{19}$, decorrente das Decisões do Conselho do Mercado Comum e das Resoluções do Grupo Mercado Comum.

Nada obstante, cumpre lembrar que o Protocolo de Brasília ${ }^{20}$ para solução de controvérsias enumerou as fontes para decisão de controvérsia no caso de chamamento para o Tribunal Arbitral, que são: art. 19 do Protocolo de Brasília, as disposições do Tratado de Assunção, os acordos celebrados no âmbito do MERCOSUL, as decisões do Conselho do Mercado Comum, as resoluções do Grupo Mercado Comum, princípios e disposições de Direito internacional aplicáveis na matéria.

Dito de outro modo, estabeleceu-se hierarquia no Protocolo de Brasília a ser observado pelo Tribunal Arbitral, porém, os outros órgãos do MERCOSUL não têm disposição alguma quanto à hierarquia ${ }^{21}$.

Importa acentuar que o Protocolo de Ouro Preto ${ }^{22}$ traz enumeração, não taxativa, das fontes jurídicas do MERCOSUL, da mesma forma que o Tratado de Assunção. Este tratado pôs fim ao período transitório desse bloco.

\footnotetext{
Ir Art.41 do Tratado de Assunção. As fontes jurídicas do MERCOSUL são: I. O Tratado de Assunção, seus protocolos e os instrumentos adicionais e complementares; II. Os acordos celebrados no âmbito do Tratado de Assunção e seus protocolos;

19. Art.41, inciso III, do Tratado de Assunção. As Decisóes do Conselho do Mercado Comum, as Resoluções do Grupo Mercado Comum e as Diretrizes da Comissão de Comércio do MERCOSUL, adotadas desde a entrada em vigor do Tratado de Assunção.

20 Incorporado ao Direito brasileiro através do Decreto n. 922, de 10 set. 1993.

2t BASSO, Maristela. As fontes do Direito do MERCOSUL. Disponvivel em http://www.jus.com.br/ doutrina/mercosu6.html. Acesso em 17.01.2001.

${ }_{22}$ Incorporado ao Direito brasileiro, através do Decreto 1901, de 09 maio 1996, no D.O.U. de 10 maio 1996. Promulgado por meio do Decreto Legislativo 188, de 15 dez. 1995.
} 
Nessa acepção, a personalidade jurídica internacional do MERCOSUL foi consolidada com o Protocolo de Ouro Preto, havendo, assim, critérios de base para negociação de acordos e um reforço considerável no poder de barganha dos quatro países em escala mundial. ${ }^{23}$ Dessa forma, ao bloco é atribuída a competência para negociar, em nome próprio, acordos com terceiros países, grupo de países e organismos internacionais.

Sendo assim, Alberto Nogueir ${ }^{24}$ avalia o desempenho no MERCOSUL assegurando que esse bloco começou a funcionar como zona de livre comércio e uma união aduaneira parcial em 12 de janeiro de 1995, com o fim do período de transição fixado no Tratado de Assunção. A união aduaneira não é plena porque há políticas comerciais diferenciadas no universo tarifário, com produtos na lista de exceções.

Registre-se, a propósito, que a união aduaneira é dotada de tarifa externa comum quando os Estados-partes aplicam uma mesma tarifa para suas importações provenientes de países não pertencentes ao bloco, isto é, a terceiros países extra-bloco, independente do produto.

De qualquer modo, o Tratado de Assunção tem o objetivo, dentre outros, de harmonização tributária. Dessa forma, tem por objeto a integração das economias, com sistemas tributários integrados com o fim da circulação econômica, com tributos sobre o valor agregado compatíveis. Com a instituição do MERCOSUL, houve imposição da TEC que passa por processo de convergência.

Está em construção a formulação da TEC definitiva ${ }^{25} \mathrm{e}$, para isso, foram trocadas informações sobre as estruturas tributárias nacionais para futura harmonização e coordenação das políticas macroeconômicas. Houve consenso, na primeira fase dos trabalhos do MERCOSUL, que a estrutura tarifária do bloco deveria contar com um número reduzido de alíquotas e com baixa dispersão $0^{26}$.

\footnotetext{
23. ALMEIDA, Paulo Roberto. MERCOSUL: fundarnentos e perspectinas, São Paulo: It:, 1998, p.52-53

24 Elba Cristina Lima Rego apud NOGUEIRA. Alberto. Globalização, regronalizaços e tributaça: a nova matriz mundial. Rio de Janeiro, Renovar, 2000. p.164-165

2 Em dez. 2000, em Florianopolis - SC - Brasil, os Estados-partes do MERCOSUI alegaram necessidades fracais para não procederem à redução integral do aumento transitório da TEC. Nesta ocasião, foi acordada a redução dos niveis tarifários adicionais para 2,5\%, com o compromisso de estabelecer estas reduçóes de acordo com cronograma a ser definido até 30,06,2001. Por ALMEIDA, Paulo Roberto de. Trajetoria do MERCOSUL em sua primeira década (1991-2001): uma avaliação politica a partir do Brasil. In: PIMENTEL, Luiz Otavio (org). Direto da integraçăo: estudos en homenagem a Werter $R$. Faria, Curitiba: Juruá, 2001. vol.2, p.315.

2. En Montevidéu, em dezembro de 1992, adotou-se o perfil tarifa externa comum, consistindo em alíquotas máxima de $20 \%$, com exceçōes, até um máximo de $35 \%$. No Ptotocolo de Ouro Preto, en 17 dezembro de 1994, foi adotada a tarifa Externa Comum, em vigor a partir de 1995. A TEC comporta algumas exceçöes temporátia para um conjunto de produtos, com desgravaçăo tarifaria gradual, Acançando integraçäo à TEC até 2006. Em 1997, houve revisão da TEC, com aumento linear de 3 ponios nas alíquotas efetivas, com aumento de $25 \%$ na tarifa média de $14 \%$ aplicada geralmente pelos paise membros. Werter R. Paria enuncia que a uniăo aduaneira, iniciada conn o Protocolo de Ouro Preto, conseguiu $80 \%$ dos produtos com inclusio na tarifa extema comum produtos esses objeto do comércio pelos quatro paises
} 
Por outro giro, com a evolução das zonas de livre comércio, surgiu a união aduaneira que não tem barreiras alfandegárias entre os países integrantes do bloco e pratica uma tributação igual em relação à importação e a exportação de mercadorias, de produtos e de serviços com destino a Estados que não façam parte da união aduaneira, com a adoção da TEC ${ }^{27}$. A próxima etapa é o mercado comum, a fase que é o objetivo do MERCOSUL.

Assinale-se, também, por Maitê Cecília Fabbri Moro ${ }^{28}$, que explica a tarifa aduaneira externa comum como elemento principal para o estágio de união aduaneira. A TEC visa a dar igual tratamento aos produtos dos países envolvidos no processo de integração quando entes venham a sair do âmbito do MERCOSUL, isso ocorre quando há acordo de tarifa igual entre os paísesmembros e que será adotada com respeito a terceiros não membros. A TEC é o elemento que movimenta a política econômica do MERCOSUL, pois implica em tomada de decisão em relação ao regime de livre câmbio ou ao protecionismo em relação ao comércio com terceiros países.

Adverte-se, agora que o art. 1o. do Tratado de Assunção estabelece que a constituição do MERCOSUL implica em livre circulação de bens, serviços e fatores produtivos entre os Estados-partes com eliminação de Direitos aduaneiros e restrições não aduaneiras à circulação de mercadorias e de qualquer medida equivalente. Um dos aspectos mais relevantes do processo de integração entre os países do MERCOSUL. Diz respeito à eliminação de diferenças legislativas que possam dificultar ou obstaculizar o seu desenvolvimento.

Sob certo aspecto, a formação do bloco econômico MERCOSUL implica em coordenação de políticas macroeconômicas, com especial referência à área fiscal e tributária, para, assim, assegurar o compromisso dos parceiros de harmonizar as suas legislações nas áreas pertinentes. Para que o desejo do MERCOSUL de harmonizar legislações se realize, é necessário buscar, em um primeiro momento, a sua coordenação. É o que se conclui da leitura do art. 10. do Tratado de Assunção.

\footnotetext{
7 FERNANDES, Edison Carlos. Sistema tributário do Mercosul. 3 ed. Säo Paulo: Revista dos Tribunais, 2001, p.5455

23 MORO, Maitê Cecilia Fabbri. Cadernos de Direitos tributáno e fmanças púbicás. Săo Paulo: Revista dos Tribunais, out/dez 1995, n.13, p.171.
} 


\section{Eficácia das decisões da união européia e do Mercosul}

A eficácia é a materialização das conseqüências que a regra imputou ao fato. $O$ fato torna-se jurídico com a incidência e torna-se eficaz com as conseqüências. As normas do MERCOSUL no Brasil estão reguladas em dois níveis. O primeiro composto por normas editadas no grau mercosulino, assim os Estados-partes criaram um sistema que prevê a eficácia das normas mercosulinas. No nível interno, o Brasil tem regras que regem a eficácia das normas emanadas de organizações internacionais e condicionam a eficácia das normas mercosulinas ${ }^{29}$.

No direito de integração, denota-se a intergovernamentabilidade e, assim, não existe transferência de competência; há a integração dos órgãos dos governos nacionais com sua própria estrutura; a estrutura do bloco é composta por representação de cada Estado e por isso a necessidade de recepção interna das regras integracionistas.

Sobre tal rubrica é necessário dizer que a estrutura institucional do MERCOSUL tem os seguintes órgãos: a) Conselho do Mercado Comum; órgão supremo do processo de integração, composta pelos ministros das relações exteriores e da economia; adota decisões; b) Grupo Mercado Comum; órgão executivo cuja função é a de assistir o conselho nas decisões de natureza executiva; adota resoluções; c) Comissão de Comércio do MERCOSUL; assiste o Grupo Mercado Comum na aplicação dos principais instrumentos de política comercial comum; d) Comissão Parlamentar Conjunta; canal de representação do parlamentos dos quatro países; e) Foro Consultivo Econômico Social; permite aos diferentes setores da sociedade (sindicatos, consumidores, sociedade civil em geral) encaminhar seus pleitos e proposições aos órgãos de decisão; f) Secretaria Administrativa, sede em Montevidéu, faz o registro das decisões tomadas pelo órgãos permanentes e facilita o processo de solução de controvérsias na fase arbitral.

Os órgãos do MERCOSUL têm natureza integovernamental, isto é, com decisões consensuais e unânimes. Seus membros são os representantes do Estados-partes e as normas não têm aplicação imediata. Há necessidade de ratificação por cada Estado-parte do MERCOSUL para eficácia da norma.

\footnotetext{
29 ALMEIDA, José Gabriel Assis de. As normas do Mercosul e a ordem juridica brasileira. In: PIMENTEL, Luiz Otávio. Direito da integração: estudos em homenagem a Werter R. Faria. Curitiba: Juruá, 2001. vol.2. p.26.
} 
A estrutura do MERCOSUL é passível de ser modificada. As normas mercosulinas prevêem a revisão da estrutura intergovernamental, além das atribuições específicas de cada órgão, por meio de conferência diplomática. $\mathrm{O}$ estudo da questão da supranacionalidade é necessária para o aprofundamento do processo de integração, mas a supranacionalidade é vista com receio pelo fato de acarretar cessão de parcela da soberania, ainda que mínima ${ }^{30}$.

Por outro lado, a União Européia é caracterizada por um sistema institucional distinto de outras organizações internacionais, porque passaram a autorizar diversos atos de delegação de soberania em benefício de órgãos independentes, os quais representam os interesses nacionais e os comunitários ao mesmo tempo, interligados por relações de complementariedade decorrente do processo de decisão ${ }^{31}$. Esse fato ocorreu após a subscrição dos Tratados de Paris ${ }^{32}$ e de Roma ${ }^{33}$.

A supranacionalidade no Direito comunitário é o reconhecimento de valores comuns aos Estados; a primazia do ordenamento comunitário; a origem contratual via fonte primária de natureza peculiar; a incorporação direta às ordens jurídicas nacionais. A supranacionalidade ocorre na formação das decisões do bloco de modo superior à vontade das partes.

A conceituação de supranacionalidade apresenta-se como noção eminentemente jurídica, configurando uma forma particular de ordenamento normativo. A noção de supranacionalidade está na acumulação de transferência do exercício de soberania permanentemente por parte dos Estados-membros em relação às comunidades. Tal instituto impõe na criação de poder efetivo em virtude da força jurídica de suas decisões ${ }^{34}$.

A definição de supranacionalidade consiste em a) existência de instâncias de decisão independentes do poder estatal, as quais estão submetidas ao seu controle; b) na superação da regra da unanimidade e do mecanismo de consenso podem ser tomadas por maioria e c) no primado do Direito comunitário: as normas originadas das instituições supranacionais têm aplicabilidade imediata nos ordenamento jurídicos internos e não necessitam de nenhuma medida de recepção dos Estados ${ }^{35}$.

\footnotetext{
${ }^{31}$ SILVA, Roberto Luiz. Direito comunitário e da integração. Porto Alegre: Síntese, 1999, p.122

31 Idem. Direito internacional público. Belo Horizonte: Inédita, 1999, p.227/228

32 Tratado de Paris, de 18 abr. 1951, criando a Comunidade Européia do Carvão e do Aço - CECA

${ }_{33}$ Tratado de Roma, de 25 jul. 1957, cria a Comunidade Econômica Européia - CEE e a Comunidade Européia da Energia Atômica - CEEA/EURATOM

${ }^{3+}$ OLIVEIRA, Odcte Maria de União européia: processo de integração e mutação. Curitiba: Juruá, 2001, p. 68-69. i5 REIS, Márcio Monteiro. MERCOSUL, União Européia e Constituição: a integração dos Estados e os ordenamentos juridicos nacionais. Rio de Janeiro: Renovar, 2001, p.65
} 
Acrescente-se às fontes do Direito comunitário, contudo, o direito secundário ou derivado do Direito comunitário que derroga todo tipo de Direito nacional, inclusive o Direito constitucional interno dos Estadosmembros da União Européia. Tem-se, assim, a) regulamentos; b) diretivas; c) decisões; d) recomendações. a) Os regulamentos ${ }^{36}$, de caráter comunitário, criam Direito igual para toda a União, aplicabilidade direta, sem necessidade de transposição para o Direito naciona ${ }^{37}$. b) Outra fonte do Direito comunitário é a diretiva, ${ }^{38}$ que não define completamente a matéria com exatidão em relação ao regulamento. As diretivas são destinadas aos Estados diretamente e necessitam de internalização ${ }^{39}$. c) Há, também, a decisão, sendo esta obrigatória em todos os seus elementos, mas apenas para os destinatários que designar, particulares, ou Estadosmembros, individualmente considerados ${ }^{40}$, e, finalmente as d) recomendações, pareceres e resoluções, que não têm caráter vinculativo.

\section{Conclusão}

A ausência de qualquer grau de supranacionalidade para a constituição do MERCOSUL impede que a harmonização das legislações se processe mediante a adoção de normas completas. As normas da Comunidade Européia incorporam-se e aplicam-se no ordenamentos nacionais destinatários, independentemente de recepção ou de normas que necessitem de internalização, como as diretivas ${ }^{41}$.

A supranacionalidade, como já se viu, tem como características principais a autonomia dos órgãos perante os Estados-membros, como ocorre na União Européia, além de normas auto-aplicáveis que prevalecem sobre as normas nacionais. No MERCOSUL, os órgãos têm natureza intergovernamental, não se acolhendo a supranacionalidade. As normas do MERCOSUL não têm aplicação imediata, diferente da União Européia.

A eficácia das decisões da União Européia e do MERCOSUL são diferentes. Este é intergovernamental e aquele é supranacional.

\footnotetext{
*xemplo de regulamentos, holandeses protestaram potque o tamanho do vaso sanitánio näo era suficientemente grande para eles; regulamento para definir o tamanho mínimo da maçã; regulamentos para a agricultura.

${ }^{37}$ SLVA, Roberto Luz. Direto comunitario e da integraço. Porto Alegre: Sintese, 1999. p.75

* Por exemplo, diretiva sobre vagem, inserto no Código Civil alemão; diretiva sobre admissĩo de advogados.

3) SILVA, Roberto Luiz. Direto comunitaro e da integrąăo. Porto Alegre: Sintese, 1999. p.76

"I FONTAINE, Pascal. A construção européta de 1945 aos nossos dias. Trad. pot José Gabriel Brasil. Lisboa: Gradiva, 1998. p.37

"1 FARIA, Werter R. Merodo de harmonização aplicáveis no MERCOSUL e incorporação das nomas contespondentes nas ordens jurdicas internas. In: Conferếnca proferida na Faculdade de Direito da Universidade da República (Uruguai), en 19.595, durante o IV Encontro Internacional de Direito da América do Sul.
} 


\section{BIBLIOGRAFIA}

ALMEIDA, Paulo Roberto. MERCOSUL: fundamentos e perspectivas. São Paulo: Ltr, 1998.

ALMEIDA, José Gabriel Assis de. As normas do Mercosul e a ordem jurídica brasileira. In: PIMENTEL, Luiz Otávio. Direito da integração: estudos em homenagem a Werter R. Faria. Curitiba: Juruá, 2001. vol.2. ALMEIDA, Paulo Roberto de. Trajetória do MERCOSUL em sua primeira década (1991-2001): uma avaliação política a partir do Brasil. In: PIMENTEL, Luiz Otávio (org.). Direito da integração: estudos em homenagem a Werter $R$. Faria. Curitiba: Juruá, 2001. vol.2

BASSO, Maristela. As fontes do Direito do MERCOSUL. Disponvível em http://www.jus.com.br/doutrina/mercosu6.html. Acesso em 17.01.2001.

CAÑAS, Gabriela. CUMBRE DE LA UE. La Declaración de Laeken. Los jefes de Estado y de Gobierno de los Quince debatirán desde marzo el futuro de la UE. In: El Pais. Disponível em http:www.elpais.es/ articulohtml'xref=20011216elpepiint_1\&type-Tes\&anchor-elpepiint\&d_date-2001121. Acesso em $17 \mathrm{dez} .2001$.

EUROPA. A nova Europa e história. Disponível em http:/ www.elpais.es/ temas/ue/menud/menud6.html. Acesso em 12 nov. 2001, p.1

FARLA, Werter R. Método de harmonização aplicáveis no MERCOSUL e incorporação das normas correspondentes nas ordens juridicas internas. In: Conferênca proferida na Faculdade de Direito da Universidade da República (Uruguai), em 19.5.95, durante o IV Encontro Internacional de Direito da América do Sul.

FERNANDES, Edison Carlos. Sistema tributário do Mercosul. 3 ed. São Paulo: Revista dos Tribunais, 2001

FERNANDES, Edison. Normas tributárias no Mercosul. In: MARTINS, Ives Gandra da Silva.(coord) O Direito tributário no Mercosul. Rio de Janeiro: Forense, 2000

FONTAINE, Pascal. A construção européia de 1945 aos nossos dias. Trad. por José Gabriel Brasil. Lisboa: Gradiva, 1998.

FORTE, Umberto. União Européa: Comunidade Econômica Européia Direito das comunidades européias e harmonização fiscal. trad. por Ana Tereza Marino Falcão. São Paulo: Malheiros, 1994. 
LAGEMANN, Eugenio. Há necessidade de um imposto único sobre o consumo no âmbito do MERCOSUL?. Seqüência. Florianópolis: Universidade Federal de Santa Catarina, 1995, vol. 16.

LIPOVETZKY, Jaime Cesar e LIPOVETZKY, Daniel Andrés. MERCOSUL, estratégia para integração: mercado comum ou zona de livre comércio?: análise e perspectivas do tratado de Assunção. São Paulo: Ltr, 1994

MEIRELLES, José Ricardo. Impostos indiretos no Mercosul e integração. São Paulo: Ltr, 2000

MORO, Maitê Cecília Fabbri. Cadernos de Direitos tributário e finanças públicas. São Paulo: Revista dos Tribunais, out/dez 1995, n.13

NOGUEIRA, Alberto. Globalização, regionalizações e tributação: a nova matriz mundial. Rio de Janeiro, Renovar, 2000.

OLIVEIRA, Odete Maria de. União européia: processo de integração e mutação. Curitiba: Juruá, 2001

REIS, Márcio Monteiro. MERCOSUL, União Européia e Constituição: a integração dos Estados e os ordenamentos jurídicos nacionais. Rio de Janeiro: Renovar, 2001

RIBEIRO, Maria de Fátima. Consideraçôes sobre a prevalência dos tratados internacionais sobre a legislaça tributária brasileira: o caso do MERCOSUL. In: Scientia Iuris, Revista do curso de mestrado em Direito negocial da UEL. Londrina: Universidade Estadual de Londrina, 1997. vol.1

SILVA, Roberto Luiz. Direito comunitário e da integração. Porto Alegre: Sintese, 1999.

TORRES, Heleno. Pluritributação internacional sobre as rendas de empresas. 2 ed. rev, atual. e ampl. São Paulo: Revista dos Tribunais, 2001 Última batalha por uma nova Europa. Relatório especial UNIR, relatório 49/2001. In: Suplemento The economist, do Jornal Valor Econômico, ed. 60. 11 dez. 2001.

VENTURA, Deisy de Freitas Lima. O futuro da União Européia: um balanço do Tratado de Nice e dos desafios da CIG 2001. In: PIMENTEL, Luiz Otávio. (org.) Direito da integração: estudos em homenagem a Werter R. Faria. Curitiba: Juruá, 2001. vol. 1, p.215. 